\title{
HDlive Image of Fetal Endocardial Cushion Defect
}

\author{
${ }^{1}$ Mohamed Ahmed Mostafa AboEllail, ${ }^{2}$ Uiko Hanaoka, ${ }^{3}$ Masato Mashima, ${ }^{4}$ Kunihiro Kawanishi, ${ }^{5}$ Toshiyuki Hata
}

\begin{abstract}
We present our first experience of constructing an image of a fetal endocardial cushion defect (ECD) employing HDlive at 21 weeks and 3 days of gestation. Conventional two-dimensional (2D) echocardiography showed an atrioventricular septal defect, bilateral ventricular hypertrophy and massive pericardial effusion. Two-dimensional color Doppler ultrasound revealed atrioventricular valve regurgitation in systole. HDlive clearly demonstrated a glossy atrial septal defect, common atrioventricular valve and bilateral ventricular hypertrophy. Moreover, free, floating leaflets of the common atrioventricular valve not attached to the interventricular septum were suspected using HDlive. These findings suggested complete ECD with congestive heart failure. HDlive provided us with a new, realistic, and arguably much improved view of the complexities and interrelationships of intracardiac structures in a case of fetal ECD. HDlive may assist in the evaluation of fetal EDC, and offer potential advantages relative to conventional 2D fetal echocardiography.
\end{abstract}

Keywords: Fetal echocardiography, Color Doppler, HDlive, Endocardial cushion defect, Congestive heart failure, Hydrops fetalis.

How to cite this article: AboEllail MAM, Hanaoka U, Mashima M, Kawanishi K, Hata T. HDlive Image of Fetal Endocardial Cushion Defect. Donald School J Ultrasound Obstet Gynecol 2014;8(4):437-439.

Source of support: Nil

Conflict of interest: None

\section{INTRODUCTION}

Endocardial cushion defects (ECDs) are congenital cardiac anomalies that occur early in fetal life due to improperly developed cardiac tissue at the center of the heart. ${ }^{1}$ Approximately $3 \%$ of children with congenital heart disease have ECDs. ${ }^{2}$ There are two types of ECD: complete ECD which involves an atrial septal defect (ASD) and a ventricular septal defect (VSD), and partial

\footnotetext{
${ }^{1}$ Research Fellow, ${ }^{2}$ Senior Assistant Professor

${ }^{3}$ Senior Resident, ${ }^{4}$ Director, ${ }^{5}$ Professor and Chairman

1-3,5Department of Perinatology and Gynecology, Kagawa University Graduate School of Medicine, Miki, Kagawa, Japan

${ }^{4}$ Department of Obstetrics and Gynecology, Marumo Ladies Clinic, Izumi Garden Tower 4F, Minato-Ku, Tokyo, Japan

Corresponding Author: Toshiyuki Hata, Professor and Chairman Department of Perinatology and Gynecology, Kagawa University Graduate School of Medicine, 1750-1 Ikenobe, Miki, Kagawa 761-0793, Japan, Phone: +81-0878912174, e-mail: toshi28@ med.kagawa-u.ac.jp
}

(or incomplete) ECD which has only an ASD, or an ASD and VSD. ${ }^{3}$ Approximately 60 to $70 \%$ of children with these anomalies have the complete form of ECD. ${ }^{1}$ Endocardial cushion defect is strongly associated with trisomy 21 , and several gene changes are also connected. However, the exact cause of ECD is unknown'. ${ }^{3}$

There have been five reports on antenatal HDlive features of normal fetal heart and congenital heart anomalies. ${ }^{4-8}$ HDlive with spatiotemporal image correlation (STIC) provides entirely new visual experiences for examiners owing to the anatomically realistic depiction of normal and abnormal fetal cardiac structures of the beating heart. ${ }^{4}$ We present our first experience of constructing an image of a fetal ECD employing HDlive at 21 weeks and 3 days of gestation.

\section{CASE REPORT}

A 21-year-old pregnant Japanese woman, gravida 1, para 0 was referred to our outpatient department at 13 weeks and 4 days of gestation because of increased nuchal translucency and fetal arrhythmia. Two-dimensional (2D) sonography (Voluson E8, GE Medical Systems, Milwaukee, WI, USA) showed increased nuchal translucency $(7.2 \mathrm{~mm})$ and fetal bradycardia. At 16 weeks and 3 days of gestation, fetal heart anomaly was suspected, but detailed information could not be obtained. There was an increase in fetal edema, and amniocentesis was performed for karyotyping. Chromosomal examination revealed a normal female karyotype.

Fetal 2D echocardiography showed an atrial septal defect, pericardial effusion, and bradycardia at 17 weeks and 5 days of gestation. Two weeks later, the fetus started to develop ascites, and bilateral ventricular hypertrophy was evident.

Two-dimensional sonography demonstrated apparent hydrops fetalis (pleural and pericardial effusions, ascites and skin edema) at 21 weeks and 3 days of gestation. A single umbilical artery was also noted. Fetal 2D echocardiography by the expert in our department showed an atrioventricular septal defect, and bilateral ventricular hypertrophy (Figs 1A to D). Two-dimensional color Doppler ultrasound revealed atrioventricular valve regurgitation in systole (Fig. 1D). HDlive clearly depicted the glossy atrial septal defect as well as ventricular septal defect, common atrioventricular valve, and bilateral ventricular hypertrophy (Figs 2A and B). Moreover, free, 

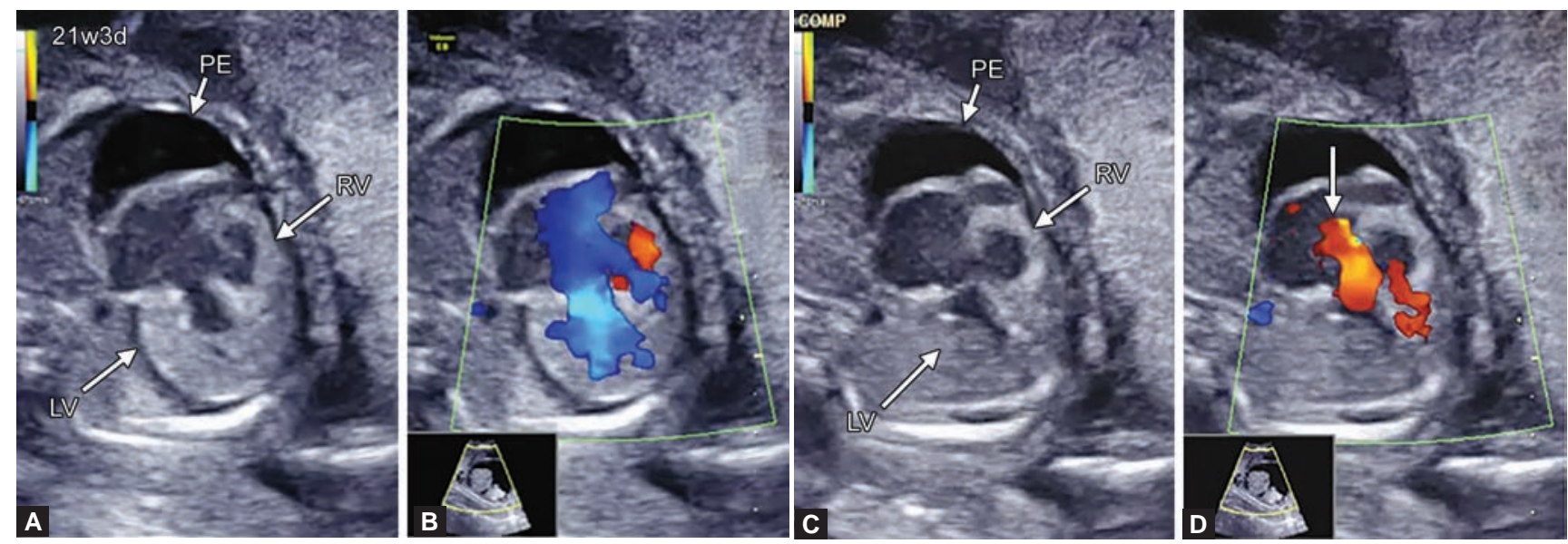

Figs 1A to D: Conventional two-dimensional echocardiographic (A and C) and color Doppler ultrasound (B and D) images of a fetal endocardial cushion defect at 21 weeks and 3 days of gestation. An atrioventricular septal defect and bilateral ventricular hypertrophy can be noted. Atrioventricular valve regurgitant flow (arrow) is also evident in systole (D): (A and B) diastole and (C and D) systole (LV: Left ventricle; PE: Pericardial effusion; RV: Right ventricle)
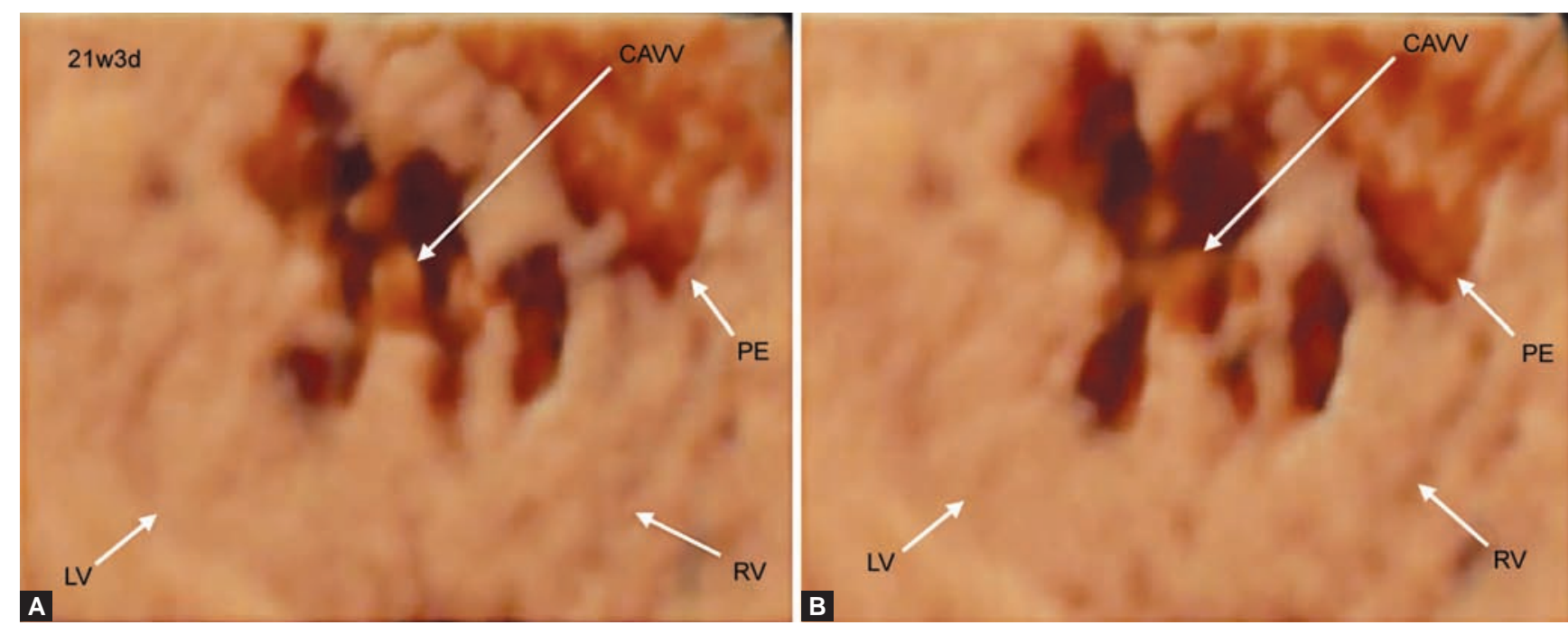

Figs 2A and B: HDlive images of an endocardial cushion defect at 21 weeks and 3 days of gestation. A glossy atrial septal defect, common atrioventricular valve (CAVV), and bilateral ventricular hypertrophy are clearly identified. Spatiotemporal anatomical relationships among CAVV, chordae, and papillary muscles can also be noted: (A) diastole and (B) systole (LV: Left ventricle; PE: Pericardial effusion; RV: Right ventricle)

floating leaflets of the common atrioventricular valve not attached to the interventricular septum were suspected using HDlive. These findings suggested complete ECD with congestive heart failure. The patient and her husband decided against continuing the pregnancy. Abortion was induced the next day, and resulted in a female abortus weighing $510 \mathrm{gm}$ (crown-heel length $=23 \mathrm{~cm}$ ). Permission to conduct an autopsy was not granted by the parents.

\section{DISCUSSION}

Characteristic 2D echocardiographic features of complete ECD involve both ASD and VSD, and only one large heart valve (common atrioventricular valve) instead of two distinct valves. ${ }^{3}$ However, it is sometimes difficult to detect the atrioventricular valve, especially when the ultrasonic beam is not perpendicular to the atrioventricular valve, because the echoes of the atrioventricular valve are confused with the interventricular septum; therefore, an accurate diagnosis of complete ECD may not be easily obtained. Moreover, the interventricular septum itself is a three-dimensional structure, so complete evaluation of the septum by 2D echocardiography is sometimes not accurate, and interventricular septal defects beneath posterior bridging leaflets of the atrioventricular valve can be missed in some patients with complete ECD. ${ }^{9}$ In the present case, $2 \mathrm{D}$ echocardiography showed an atrioventricular septal defect, bilateral ventricular hypertrophy, and pericardial effusion. However, precise depiction of the common atrioventricular valve was not possible using 2D echocardiography. HDlive clearly depicted a common atrioventricular valve. Moreover, free, floating leaflets of the common atrioventricular valve not attached to the interventricular septum were suspected using this technique. HDlive also enabled us 
to recognize spatiotemporal anatomical relationships among the common atrioventricular valve, chordae, and papillary muscles. This technique uses an adjustable light source, thus creating lighting and shadowing effects, and thereby increases depth perception. ${ }^{10}$ Therefore, anatomically realistic images of the common atrioventricular valve could be obtained in the present case. Better visualization of fetal cardiac structures with a realistic appearance was also described in previous studies on normal hearts as well as various congenital heart anomalies employing HDlive. ${ }^{4,8}$ 'HDlive may be an important modality in future fetal cardiac research and in the evaluation of fetal congenital heart disease' ${ }^{\prime}$

This, to the best of our knowledge, is the first report on antenatal HDlive features of fetal ECD. HDlive provided us with a new, realistic, and arguably much improved view of the complexities and interrelationships of intracardiac structures of fetal complete ECD. HDlive may assist in the evaluation of fetal ECD, and offer potential advantages relative to conventional 2D fetal echocardiography.

\section{ACKNOWLEDGMENTS}

The work reported in this paper was supported by a Grant-in-Aid for Scientific Research on Innovative Areas 'Constructive Developmental Science' (No. 24119004), and a Research Grant (No. 25462561) from the ministry of education, culture, sports, science and technology, Japan.

\section{REFERENCES}

1. Minnesota Department of Health. Endocardial Cushion Defect (also called atrioventricular (AV) canal or septal defects). Available at: http://www.health.state.mn.us/index.html. Accessed 9 Aug 2014.

2. Medscape. Endocardial Cushion Defects. Memdicine. medscape.com/article/154823-overview. Accessed 9 Aug 2014.

3. MedlinePlus Medical Encyclopedia. Endocardial cushion defect. Available at: http:/ /www.nlm.nih.gov/medlineplus / ency/article/007324.htm. Accessed on 9 Aug 2014.

4. Hata T, Mashima M, Ito M, Uketa E, Mori N, Ishimura M. Three-dimensional HDlive rendering images of the fetal heart. Ultrasound Med Biol 2013;39(8):1513-1517.

5. Grisolia G, Tonni G. Fetal echocardiography using HDlive. J Obstet Gynaecol Can 2013;35(6):497-498.

6. Arajo Junior E, Nardozza LMM, Moron AF. Three-dimensional ultrasound STIC-HDlive rendering: new technique to assessing of fetal heart. Braz J Cardiovasc Surg 2013;28(4):5-7.

7. Arajo Junior E, Rolo LC, Rocha LA, Marcondes L, Nardozza $\mathrm{M}$, Moron AF. The value of $3 \mathrm{D}$ and $4 \mathrm{D}$ assessments of the fetal heart. Int J Womens Health 2014;6(1):501-507.

8. Hata T, Kanenishi K, Hanaoka U, Tanaka H. HDlive of the fetal heart. Donald School J Ultrasound Obstet Gynecol 2014;8(3):266-272.

9. Smallhorn JF, Tommasini G, Anderson RH, Macartney FJ. Assessment of atrioventricular septal defects by two dimensional echocardiography. Br Heart J 1982;47(2):109-121.

10. Kagan KO, Pintoffl K, Hoopmann M. First trimester ultrasound images using HDlive. Ultrasound Obstet Gynecol 2011; 38(5):607. 